\title{
$\mathrm{Cr}(\mathrm{acac})_{3}$ in acetonitrile
}
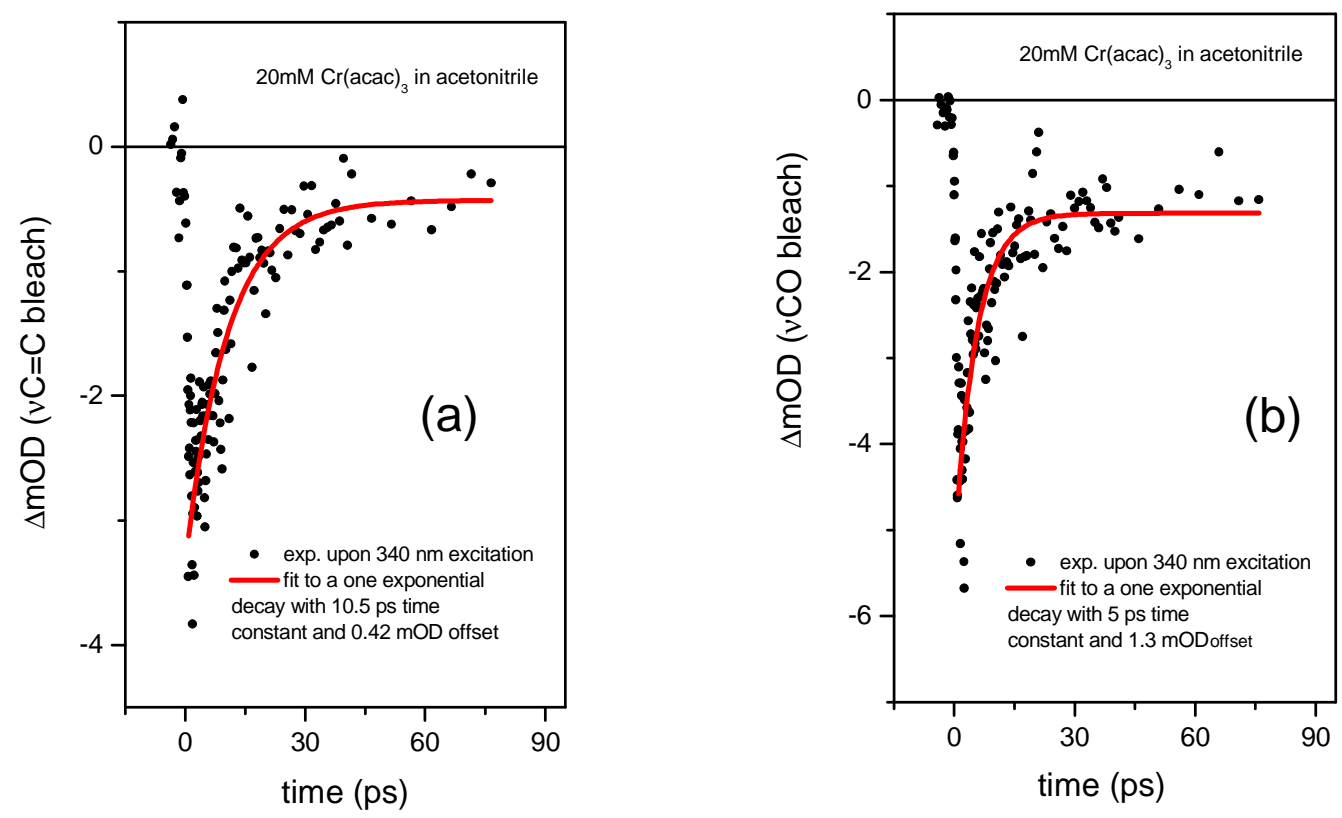

Figure 1- Bleach recovery kinetics measured for $\mathrm{Cr}(\mathrm{acac})_{3}$ in acetonitrile for (a) the $\mathrm{vC}=\mathrm{C}$ and (b) the $\mathrm{vCO}$ modes upon $340 \mathrm{~nm}$ excitation. Note that data collected in acetonitrile has somewhat higher experimental errors than in TCE due to the overlapping of the probed vibrational modes with a very strong and broad absorption of acetonitrile at $1450 \mathrm{~cm}^{-1}$, together with some technical difficulties encountered. It is therefore difficult to assess the time constant for the slow bleach recovery, which we estimate to have a contribution of about $10 \%$.

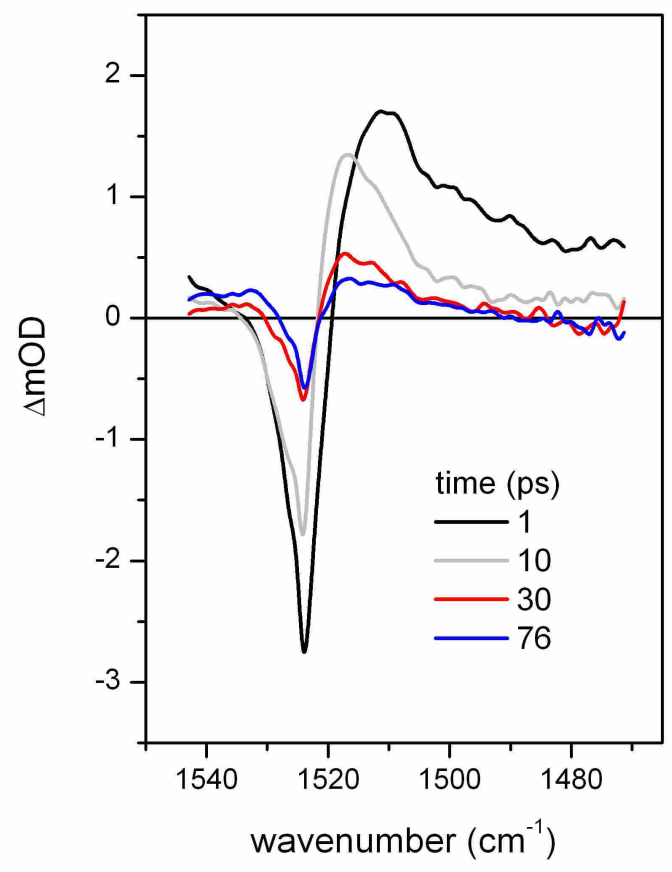

Figure 2 - Transient spectra of $\mathrm{Cr}(\mathrm{acac})_{3}$ in acetonitrile recorded in the 1540-1485 $\mathrm{cm}^{-1}$ region upon excitation at $340 \mathrm{~nm}$ at different delay times 


\section{Deactivation of ${ }^{2} \mathrm{E}$ state of $\mathrm{Cr}(\mathrm{acac})_{3}$ in tetrachloroethylene}

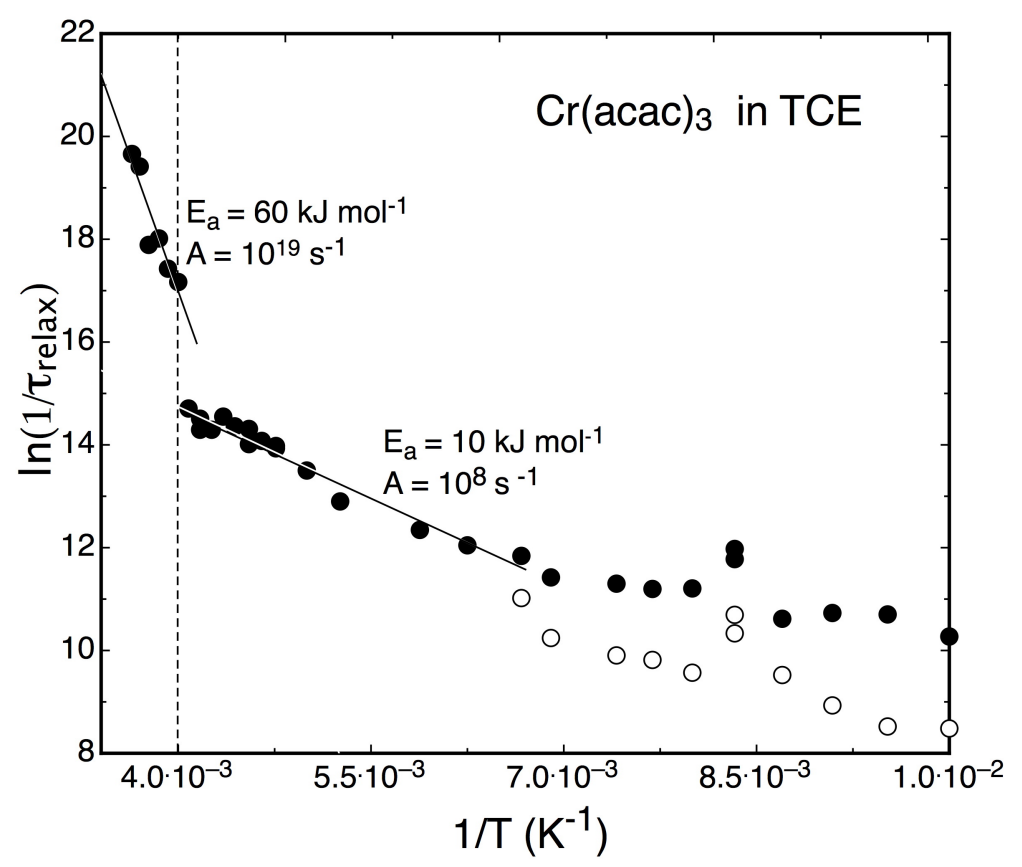

Figure 3- Arrhenius plots of the ${ }^{2} \mathrm{E} \rightarrow{ }^{4} \mathrm{~A}_{2}$ emission rate of $\mathrm{Cr}(\mathrm{acac})_{3}$ in TCE (at $\sim 800 \mathrm{~nm}$ ). The solid-liquid phase transition of the solvent is marked with a dashed line. The open circles correspond to slow component of the double exponential fit of TCE data at low temperatures

Emission measurements were carried out with a setup consisting of a liquid nitrogen cooled cryostat and a $12.5 \mathrm{~cm}$ spectrograph equipped with a gated CCD detector. Excitation pulses $(<100 \mathrm{fs})$ centered at 400 $\mathrm{nm}$ were generated by frequency doubling the $800 \mathrm{~nm}$ output of a TiSapphire femtosecond laser system The CCD detector was operated in the boxcar mode to obtain the lifetimes. Sample concentration was $1 \mathrm{mM}$. The emission decay fits well a single exponential kinetics at $\mathrm{T}>$ $160 \mathrm{~K}$, whereas at lower temperatures two exponentials are needed for satisfactory fits. An abrupt change in activation energy from $10 \mathrm{~kJ} \mathrm{~mol}^{-1}$ (solid) to $60 \mathrm{~kJ} \mathrm{~mol}^{-1}$ (liquid) is evident at the melting point $(251 \mathrm{~K})$ of the solvent. Linear extrapolation of the data to room temperature yields $\tau_{\text {relax }} \sim 600 \mathrm{ps}$. This is similar to the estimated ground state recovery time of $700 \mathrm{ps}$ in acetonitrile in ref 14 . 